$11-1-2012$

\title{
An Extension of Cochran-Orcutt Procedure for Generalized Linear Regression Models with Periodically Correlated Errors
}

\author{
Abdullah A. Smadi \\ Yarmouk University, Irbid, Jordan \\ Nour H. Abu-Afouna \\ Nourah University, Riyadh, Saudi Arabia
}

Follow this and additional works at: http://digitalcommons.wayne.edu/jmasm

Part of the Applied Statistics Commons, Social and Behavioral Sciences Commons, and the Statistical Theory Commons

\section{Recommended Citation}

Smadi, Abdullah A. and Abu-Afouna, Nour H. (2012) "An Extension of Cochran-Orcutt Procedure for Generalized Linear Regression Models with Periodically Correlated Errors," Journal of Modern Applied Statistical Methods: Vol. 11 : Iss. 2 , Article 13.

DOI: $10.22237 /$ jmasm/1351743120

Available at: http://digitalcommons.wayne.edu/jmasm/vol11/iss2/13

This Regular Article is brought to you for free and open access by the Open Access Journals at DigitalCommons@WayneState. It has been accepted for inclusion in Journal of Modern Applied Statistical Methods by an authorized editor of DigitalCommons@WayneState. 


\title{
An Extension of Cochran-Orcutt Procedure for Generalized Linear Regression Models with Periodically Correlated Errors
}

\author{
Abdullah A. Smadi \\ Nour H. Abu-Afouna \\ Yarmouk University, \\ Irbid, Jordan \\ Nourah University, \\ Riyadh, Saudi Arabia
}

An important assumption of ordinary regression models is independence among errors. This research considers the case of periodically correlated errors following the periodic AR model of order 1 (PAR(1)). The remedial measure for correlated errors in regression known as the Cochran-Orcutt procedure is generalized to the case of periodically correlated errors. The motivation for making such generalizations is that the response data may inhibit some seasonality, which may not be captured by the traditional AR(1) autoregressive model. The proposed procedure is described and the bias and MSE of the resulting intercept and slope parameter estimates of the simple LR model with errors following PAR(1) are compared with those of ordinary least squares (OLS) estimates via simulation. An application of real data is provided.

Key words: Simple linear regression model, autoregression, periodic autoregression, Cochran-Orcutt procedure, autocorrelated errors.

\section{Introduction}

Assuming that $\{\mathrm{Y} 1, \mathrm{Y} 2, \ldots, \mathrm{Yn}\}$ is an observed time series, then, using standard regression analysis suitable models of $\{\mathrm{Yt}\}$ may be developed. For example, if $\{\mathrm{Yt}\}$ consists of a deterministic trend along some random error, then $\{\mathrm{Yt}\}$ can be modeled as

$$
\mathrm{Y}_{\mathrm{t}}=\mathrm{TR}_{\mathrm{t}}+\varepsilon_{\mathrm{t}}
$$

which contains, as a special case, the linear trend model

$$
Y_{t}=\beta_{o}+\beta_{1} t+\varepsilon_{t}, t=1, \ldots, n
$$

where the $\varepsilon_{\mathrm{t}}$ 's are usually assumed independent and identically distributed (iid) $\mathrm{N}\left(0, \sigma_{\varepsilon}^{2}\right)$. This model can be generalized to other types of

Abdullah A. Smadi is an Associate Professor in the Department of Statistics. Email him at: asmadi@yu.edu.jo. Nour H. Abu-Afouna is an Instructor in the Department of Mathematics. Email her at: nouraboafouneh@yahoo.com. trends, for example the polynomial trend. If, along with the trend, $\left\{\mathrm{Y}_{\mathrm{t}}\right\}$ also contains some deterministic seasonality, then extra terms are added to the trend model to capture seasonality.

The linear trend model in (1) is a special case of the simple linear regression (SLR) model

$$
\mathrm{Y}_{\mathrm{t}}=\beta_{\mathrm{o}}+\beta_{1} \mathrm{X}_{\mathrm{t}}+\varepsilon_{\mathrm{t}}
$$

The inference of this model is straightforward. The ordinary least squares (OLS) estimators of $\beta_{o}$ and $\beta_{1}$ are given by

$$
\left.\begin{array}{l}
\hat{\beta}_{\mathrm{o}}=\overline{\mathrm{Y}}-\hat{\beta}_{1} \overline{\mathrm{X}} \\
\hat{\beta}_{1}=\frac{\mathrm{S}_{\mathrm{XY}}}{\mathrm{S}_{\mathrm{XX}}}
\end{array}\right\}
$$

and

$$
\left.\begin{array}{c}
\operatorname{Var}\left(\hat{\beta}_{\mathrm{o}}\right)=\frac{\sigma_{\varepsilon}^{2}}{\mathrm{~S}_{\mathrm{XX}}}\left[\frac{\mathrm{S}_{\mathrm{XX}}}{\mathrm{n}}+\overline{\mathrm{X}}^{2}\right] \\
\operatorname{Var}\left(\hat{\beta}_{1}\right)=\frac{\sigma_{\varepsilon}^{2}}{\mathrm{~S}_{\mathrm{XX}}}
\end{array}\right\}
$$


where $\mathrm{S}_{\mathrm{XX}}=\sum\left(\mathrm{X}_{\mathrm{i}}-\overline{\mathrm{X}}\right)^{2}$ and $\mathrm{S}_{\mathrm{XY}}=$ $\sum\left(\mathrm{X}_{\mathrm{i}}-\overline{\mathrm{X}}\right)\left(\mathrm{Y}_{\mathrm{i}}-\overline{\mathrm{Y}}\right)$. Under the assumptions of independence and constant variance, $\hat{\beta}_{\mathrm{o}}$ and $\hat{\beta}_{1}$ are the best linear unbiased estimators. In addition, they are maximum likelihood estimators under the normality assumption (Kutner, et al., 2005).

An important assumption of the model, which is frequently violated with time series data, is independence of errors $\left\{\varepsilon_{t}\right\}$. Therefore, before adopting the OLS estimates data should be tested for independence among errors. If the assumption is not satisfied, then a remedial measure should be taken (Kutner, et al., 2005). In this article a remedial measure for regression models with correlated errors, namely the Cochran-Orcutt (COR) procedure is defined and generalized to the case of periodically correlated errors.

\section{Testing for Correlated Errors}

If the assumption of independence among errors in the regression model is violated, then the standard results about OLS estimators and their properties are questionable. An important diagnostic-checking method for this assumption is the Durbin-Watson (DW) test, which is commonly used, particularly when data are related to time as in (1). The DW test assumes a first-order autoregressive (AR(1)) model for errors, that is

$$
\varepsilon_{\mathrm{t}}=\phi \varepsilon_{\mathrm{t}-1}+\mathrm{a}_{\mathrm{t}}
$$

where $u_{t}$ are assumed iid $\mathrm{N}\left(0, \sigma_{\mathrm{a}}^{2}\right)$ and $|\phi|<1$. The DW test examines the presence of first order autocorrelation among errors $(\phi \neq 0)$ against the null of white noise (WN) errors $(\phi=$ $0)$. The most common version of this test is for positive autocorrelation $(\phi>0)$ (Bowerman, et al., 2005) and the test statistic is given by

$$
\mathrm{D}=\frac{\sum_{\mathrm{t}=2}^{\mathrm{n}}\left(\mathrm{e}_{\mathrm{t}}-\mathrm{e}_{\mathrm{t}-1}\right)^{2}}{\sum_{\mathrm{t}=1}^{\mathrm{n}} \mathrm{e}_{\mathrm{t}}^{2}}
$$

where $e_{t}=Y_{t}-\hat{Y}_{t}, t=1, \ldots, n$ are the residuals of the OLS model (Kutner, et al., 2005, p. 487).

Although the DW test originally assumes an AR(1) model of errors, a significant result does not necessarily imply that the correct model of errors is AR(1) (Blattberg, 1973; Zinde-Walsh \& Galbraith, 1991). In addition, many alternatives to the DW test are available, including the runs and the Breusch-Godfrey test (Breusch, 1979; Godfrey, 1978). Thus, if the DW test is found to be significant, the best model for the errors should be identified. In general, the errors model may be extended to the wider class of auto-regressive moving average (ARMA) models (Box, et al., 1994). Assuming that the errors are correlated and follow the AR(1) model, then suitable estimation methods are required; these include, but are not limited to the generalized least squares (GLS) method (see Lee \& Lund, 2004) and the Cochran-Orcutt (COR) procedure.

Assuming that $\left\{\mathrm{Y}_{\mathrm{t}}\right\}$ (and possibly $\left\{\mathrm{X}_{\mathrm{t}}\right\}$ ) is a seasonal time series (TS) with period $\omega$, the SLR model (2) can be rewritten as

$$
\mathrm{Y}_{\mathrm{k} \omega+\mathrm{v}}=\beta_{\mathrm{o}}+\beta_{1} \mathrm{X}_{\mathrm{k} \omega+\mathrm{v}}+\varepsilon_{\mathrm{k} \omega+v}
$$

where $v=1, \ldots, \omega$ denotes the season and $\mathrm{k}$ denotes the year. In this case, if the errors in (1) are correlated, then they may inhibit some seasonality. In this case there several approaches exist to address the issue, which include adding terms to the regression model that capture seasonality as dummy variables, adding trigonometric functions or using seasonal ARMA models (Box, et al., 1994).

An alternative model is the periodic ARMA (PARMA) model (Tiao \& Grupe, 1980; Franses \& Paap, 2004). Writing the time $t$ in terms of the period $\omega$ as $k \omega+v$, the special case of the zero-mean $\operatorname{PAR}_{\omega}(1)$ model is

$$
\varepsilon_{\mathrm{k} \omega+v}=\phi_{1}(v) \varepsilon_{\mathrm{k} \omega+v-1}+\mathrm{a}_{\mathrm{k} \omega+v}, v=1, \ldots, \omega
$$

where $\left\{a_{\mathrm{k} \omega+v}\right\}$ is a zero-mean WN process with periodic variances $\sigma_{\mathrm{a}}^{2}(v)$ and $\phi_{1}(v)$ is the AR parameter of season $v$. If the period $\omega=1$, then this model reduces to the AR(1) model (5). It is assumed that this model is periodic stationary, 


\section{SMADI \& ABU-AFOUNA}

that is, $\left|\prod_{v=1}^{\omega} \phi_{1}(v)\right|<1 \quad$ (Obeysekera \& Salas, 1986). The properties of the OLS estimates of the SLR model when the errors are PAR(1) were investigated by Smadi and Abu-Afouna (2012). They also developed a GLS estimation for LR models under this setting of errors. PARMA models, which were first used in hydrology, are suitable for modeling periodic correlations; they have since become common in economic and other areas (Obeysekera \& Salas, 1986; Franses \& Paap, 2004).

The power of the DW test when errors are PAR(1) was investigated by Albertson, et al. (2002) who showed that the test is usually significant in this case. The DW test is, therefore, a good method to detect autocorrelations among errors, but it does not necessarily correctly identify its model (Lee \& Lund, 2004).

An alternative test to the DW test was proposed by McLeod (1995). This test is designed for testing periodically autocorrelated errors. Assuming $n=m \omega$, then the residual $\left\{e_{t}\right\}$ is rewritten as $\left\{\mathrm{e}_{\mathrm{k} \omega+v}\right\}$ for $\mathrm{k}=0, \ldots, \mathrm{m}-1$ and $\mathrm{v}=$ $1, \ldots, \omega$; thus, the season-wise residuals can be obtained. For example, $v=1,\left\{\mathrm{e}_{1}, \mathrm{e}_{\omega+1}, \ldots, \mathrm{e}_{(\mathrm{m}-}\right.$ 1) $\omega+1\}$ are the residuals for season 1 , therefore, the first lag sample autocorrelation for season $v$ is

$$
r_{1}(v)=\frac{C_{1}(v)}{\sqrt{C_{o}(v) C_{o}(v-1)}},
$$

where $C_{0}(v)$ and $C_{1}(v)$ are the sample variance for season $v$ and the first lag sample seasonal autocovariance of season $v$, respectively, are given by

$$
C_{o}(v)=\frac{\sum_{j=0}^{m-1}\left(e_{j \omega+v}-\bar{e}_{v}\right)^{2}}{m-1}
$$

and

$$
C_{1}(v)=\frac{\sum_{j=0}^{m-1}\left(e_{j \omega+v}-\bar{e}_{v}\right)\left(e_{j \omega+v-1}-\bar{e}_{v-1}\right)}{m-1} .
$$

McLeod demonstrated that $\mathrm{L}=\mathrm{n} \sum_{\mathrm{v}=1}^{\omega}\left(\mathrm{r}_{1}(\mathrm{v})\right)^{2}$ is asymptotically distributed as a Chi-square with $\omega$ degrees of freedom under the assumption that there is no autocorrelation in the first lag for all seasons; thus, if $L>\chi_{\omega, \alpha}^{2}$ then it may be concluded that the errors are periodically autocorrelated. This test is implemented in $\mathrm{R}$ via the pear library (McLeod \& Balcilar, 2008).

Generalization of Cochran-Orcutt Procedure for Errors Following PAR(1)

If error terms are autocorrelated, then the parameter estimation of the regression model is not straightforward. Assuming that the errors follow the AR(1) model (5), the SLR model in (2) is renamed as the generalized simple linear regression (GLR) model (Kutner, et al., 2005, p. 484). In this case, this model can be rewritten as (Kutner, et al., 2005, p. 491):

$$
Y_{t}^{\prime}=\beta_{o}^{\prime}+\beta_{1}^{\prime} X_{t}^{\prime}+a_{t}, t=1, \ldots, n
$$

where

$$
\begin{gathered}
\left.\begin{array}{c}
Y_{t}^{\prime}=Y_{t}-\rho Y_{t-1} \\
X_{t}^{\prime}=X_{t}-\rho X_{t-1}
\end{array}\right\} \\
\left.\begin{array}{c}
\beta_{o}^{\prime}=\beta_{o}(1-\rho) \\
\beta_{1}^{\prime}=\beta_{1}
\end{array}\right\}
\end{gathered}
$$

and

$$
\mathrm{a}_{\mathrm{t}}=\varepsilon_{\mathrm{t}}-\rho \varepsilon_{\mathrm{t}-1}, \mathrm{t}=1, \ldots, \mathrm{n}
$$

where $\left\{a_{t}\right\}$ is uncorrelated. Thus, (8) is a standard SLR model and the estimation of $\beta_{\mathrm{o}}$ and $\beta_{1}$ begins by estimating $\rho$, then estimating $\beta_{\mathrm{o}}^{\prime}$ and $\beta_{1}^{\prime}$ in (8) and finally obtaining estimates for $\beta_{0}$ and $\beta_{1}$ using (10). Several methods exist for estimating $\rho$ in this situation, including the COR and Hildreth-Lu procedures (Kutner, et al., 2005). This study only considers the CochraneOrcutt procedure, which involves an iteration of three steps (Kutner, et al., 2005, p. 492):

1. Estimation of $\rho$. This is accomplished by noting that the autoregressive error process assumed in model (2) can be viewed as a regression through the origin: 


$$
\varepsilon_{\mathrm{t}}=\rho \varepsilon_{\mathrm{t}-1}+\mathrm{a}_{\mathrm{t}}, \mathrm{t}=1, \ldots, \mathrm{n} .
$$

Because $\varepsilon_{\mathrm{t}}$ and $\varepsilon_{\mathrm{t}-1}$ are unknown, residuals $\mathrm{e}_{\mathrm{t}}$ and $e_{t-1}$ obtained by OLS are used as the response and predictor variables, respectively, and $\rho$ is estimated by fitting a straight line through the origin so that the moment estimator of the slope $\rho$ is:

$$
\hat{\rho}=\frac{\sum_{t=1}^{n} e_{t-1} e_{t}}{\sum_{t=2}^{n} e_{t-1}^{2}} .
$$

2. Fitting of transformed model (8). Using the estimate $\hat{\rho}$ in (12), the transformed variables $Y_{t}^{\prime}$ and $X_{t}^{\prime}$ in (9) are obtained and OLS is used with these transformed variables to yield the fitted regression function as:

$$
\hat{Y}_{t}^{\prime}=\hat{\beta}_{o}^{\prime}+\hat{\beta}_{1}^{\prime} X_{t}^{\prime}
$$

3. The DW test is employed to test whether the error terms for the transformed model are uncorrelated. If the test indicates that they are uncorrelated, the procedure terminates and $\hat{\beta}_{\mathrm{o}}$ and $\hat{\beta}_{1}$ are obtained based on $\hat{\beta}_{\mathrm{o}}^{\prime}$ and $\hat{\beta}_{1}^{\prime}$ in the Step 2 and by using (10).

4. If the DW test in Step 3 is significant, then steps (1)-(3) are repeated for $Y^{\prime}$ and $X^{\prime}$ in place of $\mathrm{Y}$ and $\mathrm{X}$, and this continues until the DW test indicates that error terms are uncorrelated.

5. An estimate of $\sigma_{\varepsilon}^{2}$ is given by (Kutner, et al., 2005, p. 487) as:

$$
\hat{\sigma}_{\varepsilon}^{2}=\frac{\hat{\sigma}_{a}^{2}}{1-\hat{\rho}^{2}}
$$

where $\hat{\sigma}_{a}^{2}$ is the sample variance of residuals obtained from the fitted regression model in Step 2.
Consider the GLR model (2) with error terms following the zero-mean $\operatorname{PAR}_{\omega}(1)$ model (7). The COR procedure described is now generalized to the GLR model with PAR(1) errors. Assuming that $Y_{t}$ and $X_{t}$ are seasonal time series with period $\omega,(2)$ and (7) can be restated as:

$$
\left.\begin{array}{c}
\mathrm{Y}_{\mathrm{k}, v}=\beta_{\mathrm{o}}+\beta_{1} \mathrm{X}_{\mathrm{k}, \mathrm{v}}+\varepsilon_{\mathrm{k}, \mathrm{v}}, \\
\varepsilon_{\mathrm{k}, \mathrm{v}}=\phi_{1}(v) \varepsilon_{\mathrm{k}, \mathrm{v}-1}+\mathrm{a}_{\mathrm{k}, \mathrm{v}}
\end{array}\right\}
$$

where the time $\mathrm{k}$ denotes the year and $v=1,2$, $\ldots, \omega$ denotes the season.

Theorem 1

The generalized regression model (13) is equivalent to:

$$
\mathrm{Y}_{\mathrm{k}, \mathrm{v}}^{\prime}=\beta_{o}^{\prime}(\mathrm{v})+\beta_{1}^{\prime}(v) \mathrm{X}_{\mathrm{k}, \mathrm{v}}^{\prime}+a_{\mathrm{k}, \mathrm{v}}
$$

with

$$
\left.\begin{array}{c}
\mathrm{Y}_{\mathrm{k}, \mathrm{v}}^{\prime}=Y_{\mathrm{k}, \mathrm{v}}-\varphi_{1}(\mathrm{v}) Y_{\mathrm{k}, \mathrm{v}-1} \\
\mathrm{X}_{\mathrm{k}, v}^{\prime}=X_{\mathrm{k}, v}-\varphi_{1}(v) X_{\mathrm{k}, \mathrm{v}-1} \\
\beta_{o}^{\prime}(\mathrm{v})=\beta_{o}\left(1-\varphi_{1}(\mathrm{v})\right) \\
\beta_{1}^{\prime}(v)=\beta_{1}
\end{array}\right\} .
$$

Proof 1

Substituting for $Y_{k, v}$ and $Y_{k, v-1}$ form (13) in $\mathrm{Y}_{\mathrm{k}, \mathrm{v}}^{\prime}=\mathrm{Y}_{\mathrm{k}, \mathrm{v}}-\phi_{1}(v) \mathrm{Y}_{\mathrm{k}, \mathrm{v}-1}$ gives

$$
\begin{aligned}
Y_{k, v}^{\prime}= & \left(\beta_{o}+\beta_{1} X_{k, v}+\varepsilon_{k, v}\right) \\
& -\varphi_{1}(v)\left(\beta_{o}+\beta_{1} X_{k, v-1}+\varepsilon_{k, v}\right) \\
= & \beta_{o}\left(1-\varphi_{1}(v)\right)+\beta_{1}\left(X_{k, v}-\varphi_{1}(v) X_{k, v-1}\right) \\
& +\left(\varepsilon_{k, v}-\varphi_{1}(v) \varepsilon_{k, v-1}\right)
\end{aligned}
$$

The transformed model in (14) is a GLR model with errors following a seasonal white noise process with periodic coefficients. To estimate the parameters of this model note that (14) defines a standard regression model for each season separately. That is, to estimate $\beta_{\mathrm{o}}^{\prime}(1), \quad \beta_{1}^{\prime}(1)$ and $\sigma_{\mathrm{a}}^{2}(1)$ only the data for $\mathrm{Y}_{\mathrm{k}, 1}^{\prime}$ and $\mathrm{X}_{\mathrm{k}, 1}^{\prime}$ is used.To summarize the generalized 


\section{SMADI \& ABU-AFOUNA}

COR procedure for errors following the PAR $\omega(1)$ model:

1. Using the OLS method, regress $Y_{t}$ on $X_{t}$ to obtain the residuals $\left\{\mathrm{e}_{\mathrm{t}}\right\}$.

2. Apply the DW test for autocorrelation among residuals; if residuals are not autocorrelated then the procedure terminates.

3. Estimate $\phi_{1}(v)$ by regressing $Y_{k, v}$ on $X_{k, v}$ for each season $v=1,2, \ldots, \omega$ separately, then obtain the residual for each $\operatorname{model} \mathrm{e}_{\mathrm{k}, \mathrm{v}}^{*}$. Estimate $\phi_{1}(v)$ using:

$$
\hat{\varphi}_{1}(v)=\frac{\sum_{\mathrm{k}=1}^{\mathrm{m}} \mathrm{e}_{\mathrm{k}, v-1}^{*} \mathrm{e}_{\mathrm{k}, v}^{*}}{\sum_{\mathrm{k}=1}^{\mathrm{m}}\left(\mathrm{e}_{\mathrm{k}, v-1}^{*}\right)^{2}} .
$$

4. Compute $\mathrm{Y}_{\mathrm{k}, v}^{\prime}$ and $\mathrm{X}_{\mathrm{k}, v}^{\prime}$ using (15) and the estimates in (16), then regress $Y_{k, v}^{\prime}$ on $X_{k, v}^{\prime}$ for data in each season $v$, separately. This results in $\beta_{o}^{\prime}(v), \beta_{1}^{\prime}(v)$ and

$$
\hat{\sigma}_{\mathrm{a}}^{2}(v)=\frac{\sum_{\mathrm{k}=1}^{\mathrm{m}}\left(\mathrm{e}_{\mathrm{k}, v}^{\prime}\right)^{2}}{\mathrm{~m}-2} .
$$

5. Apply the DW test on $\left\{\mathrm{e}_{\mathrm{k}, v}^{\prime}\right\}$ for each season $v=1,2, \ldots, \omega$. If none of the cases is significant then the procedure terminates. If, however, in some seasons the DW test is significant then the ordinary COR procedure is applied to those seasons until the DW test is found to be insignificant for all seasons

6. Using $\beta_{o}^{\prime}(v), \beta_{1}^{\prime}(v)$ and (15) find $\hat{\beta}_{o}$ and $\hat{\beta}_{1}$, which are unbiased estimators of $\beta_{0}$ and $\beta_{1}$ denoted as $\hat{\beta}_{\text {ov }}$ and $\hat{\beta}_{1 v}, v=1,2, \ldots, \omega$.

7. Step 6 results in $\omega$ estimates of $\beta_{o}$ and $\beta_{1}$, thus $\beta_{0}$ and $\beta_{1}$ may be estimated by the average of these estimates:

$$
\begin{aligned}
& \tilde{\beta}_{\mathrm{o}}=\frac{1}{\omega} \sum_{v=1}^{\omega} \hat{\beta}_{\mathrm{ov}} \\
& \text { and } \\
& \tilde{\beta}_{1}=\frac{1}{\omega} \sum_{v=1}^{\omega} \hat{\beta}_{1 v}
\end{aligned}
$$

To estimate the variances of $\left\{\varepsilon_{t}\right\}$, (7) results in

$\sigma_{\varepsilon}^{2}(v)=\varphi_{1}^{2}(v) \sigma_{\varepsilon}^{2}(v-1)+\sigma_{\mathrm{a}}^{2}(v) ; v=1,2, \ldots, \omega$.

Replacing $\phi_{1}(v)$ and $\sigma_{\mathrm{a}}^{2}(v)$ with the estimates obtained results in a system of $\omega$ equations that can be solved for $\sigma_{\varepsilon}^{2}(v)$.

It should be emphasized that the PAR models were chosen because they allow for periodic correlations between successive seasons that need not be homogeneous. Franses and Paap (2004) showed that many business time series data sets inhibit periodic autocorrelations. McLeod (1995) showed that the errors resulting from fitting seasonal ARMA models for several real-time series have periodic autocorrelations. Albertson and Aylen (1999) identified a PAR error process in modeling scrap steel market. Lastly, according to Osborn, et al. (1988), failure to allow for periodicity in time series data may bias specification tests and further complicate the modeling process.

OLS and COR Estimator Comparison

Estimates of $\beta_{0}$ and $\beta_{1}$ for the OLS method and the generalized COR method are next discussed and compared via bias and MSE using Monte-Carlo simulation; the focus is on the estimates of $\beta_{0}$ and $\beta_{1}$ only. For the simulation, an R-code was developed by the authors to run 2,000 repetitions each of realization length $4 \mathrm{n}(\mathrm{n}=30,50,100)$ for pairs of data $(\mathrm{X}, \mathrm{Y})$. The simulation ran as follows:

1. Generate the predictor values $\mathrm{X}_{\mathrm{t}}=\mathrm{t}+$ $2 \operatorname{Cos}(2 \pi t / 4), t=1, \ldots, 4 n$.

2. Generate the errors $\left\{\varepsilon_{1}, \varepsilon_{1}, \ldots, \varepsilon_{\text {n }}\right\}$ from the zero mean $\mathrm{PAR}_{4}(1)$ model: $\varepsilon_{\mathrm{k}, v}=\phi_{1}(\mathrm{v}) \varepsilon_{\mathrm{k}, v-1}+\mathrm{a}_{\mathrm{k}, v}$, with $\phi_{1}(1)=-0.9$, 
$\phi_{1}(2)=0.6, \phi_{1}(3)=0.3, \phi_{1}(4)=-0.8$ and $\left\{\mathrm{a}_{\mathrm{k}, \mathrm{v}}\right\}$ is a seasonal $\mathrm{WN} \sim \mathrm{N}\left(0, \sigma_{\mathrm{a}}^{2}(v)\right)$ with $\sigma_{\mathrm{a}}^{2}(1)=100, \quad \sigma_{\mathrm{a}}^{2}(2)=1, \quad \sigma_{\mathrm{a}}^{2}(3)=1 \quad$ and $\sigma_{\mathrm{a}}^{2}(4)=10$.

3. Compute $Y_{t}=2+50 X_{t}+\varepsilon_{t} ; t=1, \ldots, 4 n$.

4. Regress $Y_{t}$ on $X_{t}$ to obtain the OLS estimates $\hat{\beta}_{0}$ and $\hat{\beta}_{1}$. Apply Steps 1-7 of the generalized COR procedure and obtain $\widetilde{\beta}_{\mathrm{o}}$ and $\widetilde{\beta}_{1}$ using (17).

Based on the realizations, the bias and MSE of estimates $\beta_{0}$ and $\beta_{1}$ for both the OLS and COR methods were computed and are presented in Table 1. The resulting OLS estimates are not reliable regardless of bias and MSE because the assumptions of the SLR model are not satisfied. Notice that the bias and MSE of estimates of $\beta_{0}$ and $\beta_{1}$ for both methods decrease as $n$ increases. The proposed method estimates dominate the OLS estimates both in view of bias and MSE. Finally, the differences in bias and MSE for both methods were more apparent for the estimates of $\beta_{\mathrm{o}}$ compared to those for $\beta_{1}$.

Table 1: Bias and MSE (in brackets) of $\beta_{0}$ and $\beta_{1}$ Estimates

\begin{tabular}{|c|c|c|c|c|}
\hline \multirow[b]{2}{*}{$\mathrm{n}$} & \multicolumn{2}{|c|}{ OLS } & \multicolumn{2}{|c|}{ COR } \\
\hline & $\hat{\beta}_{\text {o }}$ & $\hat{\beta}_{1}$ & $\widetilde{\beta}_{\mathrm{o}}$ & $\widetilde{\beta}_{1}$ \\
\hline 30 & $\begin{array}{c}0.0003 \\
(0.0006)\end{array}$ & $\begin{array}{c}0.0206 \\
(3.0510)\end{array}$ & $\begin{array}{c}-0.0055 \\
(0.6821)\end{array}$ & $\begin{array}{c}-0.000005 \\
(0.0001)\end{array}$ \\
\hline 50 & $\begin{array}{c}-0.0003 \\
(0.0360)\end{array}$ & $\begin{array}{c}0.0360 \\
(1.8351)\end{array}$ & $\begin{array}{c}-0.0163 \\
(0.3137)\end{array}$ & $\begin{array}{c}0.00008 \\
(0.00002)\end{array}$ \\
\hline 100 & $\begin{array}{c}-0.0001 \\
(0.00001)\end{array}$ & $\begin{array}{c}0.0076 \\
(0.9399)\end{array}$ & $\begin{array}{c}-0.0049 \\
(0.1389)\end{array}$ & $\begin{array}{c}0.000003 \\
(0.000002)\end{array}$ \\
\hline
\end{tabular}

Application to Real Data

Consider quarterly U.S. airline passenger-miles (in millions). The data (which was originally monthly but was aggregated to quarterly) shows 9 years from 1996 to 2004 (Cryer \& Chan, 2008). Figure 1 shows the data, denoted by $\mathrm{Yt} ; \mathrm{t}=1, \ldots, 36$. The time series shows both a nearly increasing trend and an apparent seasonality. This data set is used to illustrate the proposed method as discussed previously. The generalized COR procedure was applied as follows:

1. The linear trend model was fitted for $Y_{t}$ and $\hat{Y}_{t}=104.608+0.866 t$. Assuming the errors are $\mathrm{WN}$, the estimated error variance is the MSE of the OLS regression, that is, $\hat{\sigma}_{\varepsilon}^{2}=$ 2771.9.

2. Based on the residuals $\left\{\mathrm{e}_{\mathrm{t}}\right\}$ in Step 1 the DW test was applied and resulted in a significant $\mathrm{p}$-value of 0.003 . To check that the errors are periodically autocorrelated the McLeod test was also applied on $\left\{\mathrm{e}_{\mathrm{t}}\right\}$ with period $\omega$ $=4$. The p-value equals 0.00009 , which is also highly significant; this indicates that there is sufficient evidence to suggest that the errors are periodically autocorrelated. Figure 2 shows the variability among residuals for various quarters; the $\mathrm{ACF}$ shows significant correlations at lag one, which agrees with the DW test, and is also significant at lag four, which is the seasonal lag.

3. $Y_{t}$ and $t$ are subdivided by quarters. For each $v=1, \ldots, 4, Y_{k, v}$ is regressed on $t_{k, v}, k=1$, ..., 9. The four fitted regression models were:

$$
\begin{aligned}
& \hat{\mathrm{Y}}_{\mathrm{k}, 1}=99.544+0.733 \mathrm{t}_{\mathrm{k}, 1} \\
& \hat{\mathrm{Y}}_{\mathrm{k}, 2}=108.495+0.925 \mathrm{t}_{\mathrm{k}, 2} \\
& \hat{\mathrm{Y}}_{\mathrm{k}, 3}=110.877+0.914 \mathrm{t}_{\mathrm{k}, 3} \\
& \text { and } \\
& \hat{\mathrm{Y}}_{\mathrm{k}, 4}=100.211+0.847 \mathrm{t}_{\mathrm{k}, 4}
\end{aligned}
$$

thus, $\quad \hat{\varphi}_{1}(1)=0.733, \quad \hat{\varphi}_{2}(2)=0.925$, $\hat{\varphi}_{3}(3)=0.914$ and $\hat{\varphi}_{4}(4)=0.847$. 


\section{SMADI \& ABU-AFOUNA}

Figure 1: Time Series Plot of Quarterly U.S. Airline Passenger Miles, 1996-2004

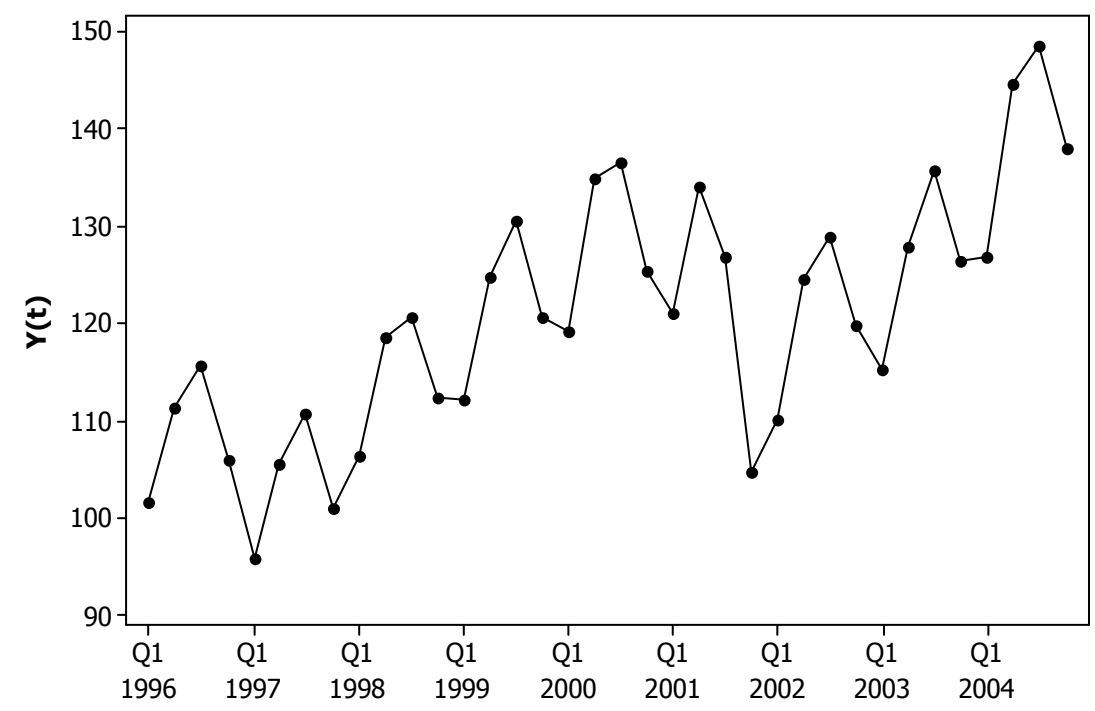

Figure 2: The Parallel Box Plot of Residuals (top) and ACF of Residuals (bottom) for the fitted OLS Model
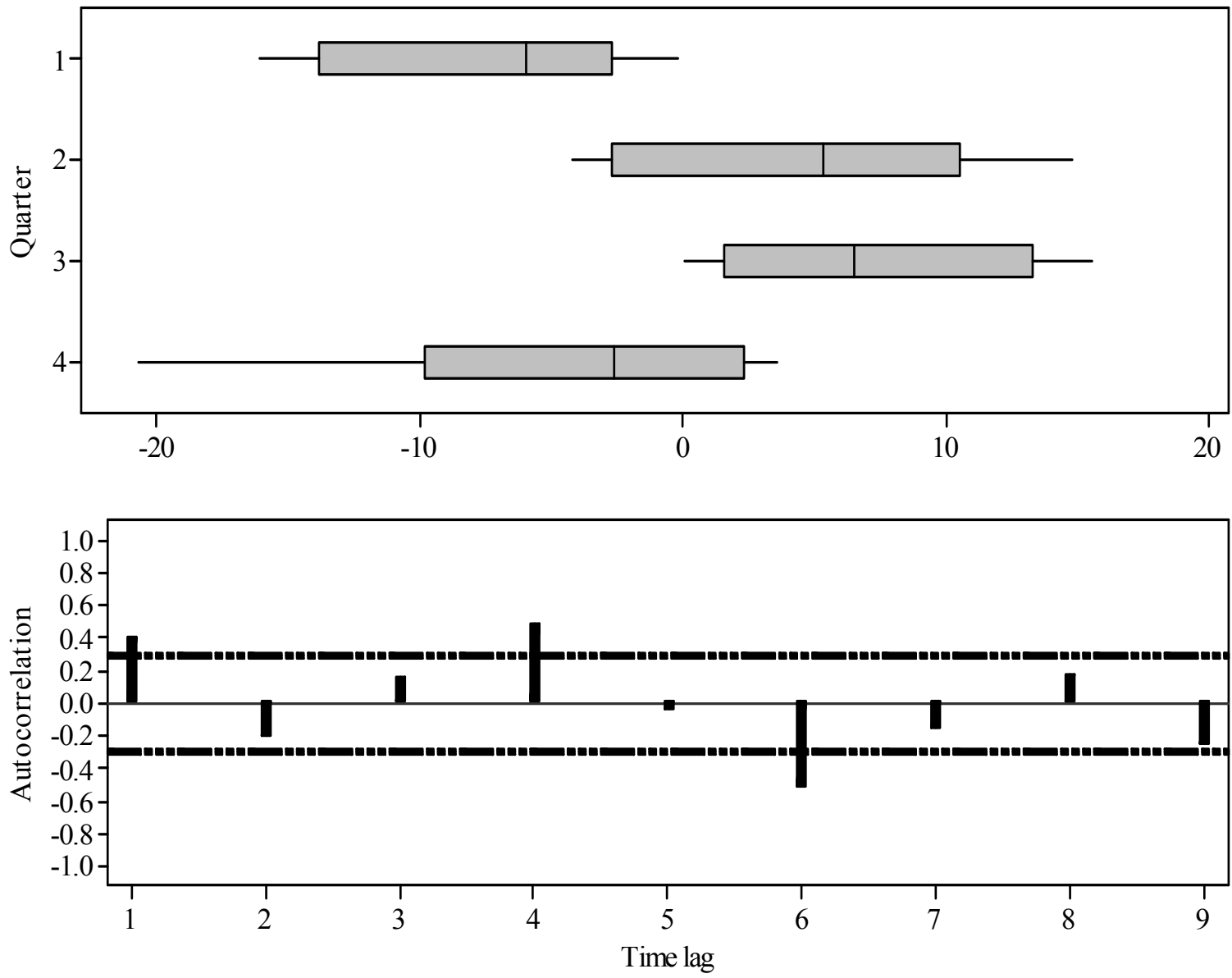
4. $\mathrm{Y}_{\mathrm{k}, v}^{\prime}$ and $\mathrm{t}_{\mathrm{k}, v}^{\prime}$ were obtained using (15). Results obtained when regressing $\mathrm{Y}_{\mathrm{k}, \mathrm{v}}^{\prime}$ on $\mathrm{t}_{\mathrm{k}, v}^{\prime}$ for each quarter separately (see Table 2).

Table 2: Estimates of Transformed Regressions for Various Quarters

\begin{tabular}{|c|c|c|c|}
\hline$v$ & $\hat{\beta}_{\mathrm{o}}^{\prime}(v)$ & $\hat{\beta}_{1}^{\prime}(v)$ & $\hat{\sigma}_{\mathrm{a}}^{2}(v)$ \\
\hline 1 & 23.081 & 1.081 & 18.045 \\
\hline 2 & 14.339 & 3.190 & 4.135 \\
\hline 3 & 10.527 & 1.210 & 18.181 \\
\hline 4 & 6.0950 & 0.584 & 22.482 \\
\hline
\end{tabular}

5. The residuals $\left\{e_{k, v}^{\prime}\right\}$ for each season $v=1$, ..., 4 were computed from the fitted models in Step 4 and the DW test is applied for each season. It was found that $\mathrm{p}$-values for all tests were: $0.481,0.317,0.273$ and 0.419 , thus, not all are significant so that the iterations terminate.

6. $\hat{\beta}_{\text {ov }}$ and $\hat{\beta}_{1 v}$ were obtained as shown in Step 6 of the proposed method described previously and are based on (15). Each season $v$ separately gave:

$$
\begin{array}{ll}
\hat{\beta}_{\mathrm{o} 1}=86.468, & \hat{\beta}_{11}=1.081 \\
\hat{\beta}_{\mathrm{o} 2}=190.195, & \hat{\beta}_{12}=3.190 \\
\hat{\beta}_{\mathrm{o} 3}=122.848, & \hat{\beta}_{13}=1.210 \\
\hat{\beta}_{04}=39.937, & \hat{\beta}_{14}=0.584
\end{array}
$$

Using these estimates and (17) results in $\widetilde{\beta}_{\mathrm{o}}=109.862$ and $\widetilde{\beta}_{1}=1.516$.

7. Estimates of the variances of $\left\{\varepsilon_{t}\right\}$ were obtained using (18) and equal

$$
\begin{aligned}
& \hat{\sigma}_{\varepsilon}^{2}(1)=53.128, \\
& \hat{\sigma}_{\varepsilon}^{2}(2)=49.555, \\
& \hat{\sigma}_{\varepsilon}^{2}(3)=59.607, \\
& \hat{\sigma}_{\varepsilon}^{2}(4)=65.284 .
\end{aligned}
$$

Note that the resulting estimate of intercept in Step 6 is very close to that of the OLS estimate in Step 1, however, a larger difference is detected in the estimate of the slope parameter. This is due to the fact that the slope is directly affected by the periodic correlations. The largest effect was observed on the estimate of the error terms, which was very large assuming WN errors (see Step 1) compared to estimates that account for periodic correlations in Step 7.

Finally, it should be noted that the objective of this application is for illustration of the proposed method. The magnitudes of differences between OLS and the proposed method estimates do not necessarily count for our method, meaning that, after the errors are correlated the OLS estimates and their standard errors are not reliable. Because this article focuses on the fact that in standard regression analysis, particularly when dealing with time series data, routine residual analysis should test for autocorrelation among errors and detemine whether it is a traditional AR(1) autocorrelation or periodic.

\section{Conclusion}

This study examined the SLR model with correlated errors. The ordinary Cochran-Orcutt procedure for SLR models with correlated errors with AR(1) model was generalized to the case of periodically correlated errors as a PAR(1) model, which produced estimates of regression parameters $\beta_{\mathrm{o}}$ and $\beta_{1}$. Monte Carlo simulations were used to compare the ability of both methods to estimate $\beta_{\mathrm{o}}$ and $\beta_{1}$ via bias and MSE. Results indicate that the estimates based on the proposed COR procedure dominate the OLS estimates.

This study was designed to consider the fact that errors in ordinary regression analysis may exhibit periodic autocorrelation which can be modeled by a PAR(1) model and not 


\section{SMADI \& ABU-AFOUNA}

necessarily an AR(1) model. The proposed method is by no means the best remedial measure for periodic correlations. Future research may add seasonal dummies to the regression model or to use generalized least squares regression.

\section{References}

Albertson, K., \& Aylen, J. (1999). Forecasting using a periodic transfer function with an application to the UK price of ferrous scrap. International Journal of Forecasting, 15, 409-419.

Albertson, K., Aylen, J. \& Lim, K. B. (2002). The power of the Durbin Watson test when the errors are PAR(1). Journal of Statistical Computation and Simulation, 72, 507-516.

Blattberg, R. (1973). Evaluation of the power of the Durbin-Watson statistic for nonfirst order serial correlation alternatives. Journal Review of Economics \& Statistics, 55, 508-515.

Breusch, T. (1979). Testing for autocorrelation in dynamic linear models. Australian Economic Papers, 17, 334-355.

Box, G., Jenkins, G., \& Reinsel, G. (1994). Time series analysis, forecasting and control, $3^{\text {rd }} \mathrm{Ed}$. Englewood Cliffs, NJ: PrenticeHall.

Bowerman, B., O'Connell, R., \& Koehler, A. (2005). Forecasting, time series and regression, an applied approach, $4^{\text {th }} \mathrm{Ed}$. Belmont, CA.:Thomson Brooks/Cole.

Cryer, J. D., \& Chan, K. (2008). Time series analysis with applications in $R, 2^{\text {nd }} \mathrm{Ed}$. New York: Springer-Verlag.

Franses, P., \& Paap, R. (2004). Periodic time series models. Oxford, UK: Oxford University Press.
Godfrey, L. (1978). Testing against general autoregressive and moving average error models when the regressors include lagged dependent variables. Econometrica, 46, 12931302.

Kutner, H., Nachtsheim, J., Neter, J., \& Li, W. (2005). Applied Linear Statistical Models, $5^{\text {th }} E d$. LONDON: McGraw-Hill.

Lee, J., \& Lund, R. (2004). Revisiting simple linear regression with autocorrelated errors. Biometrika, 91, 240-245.

McLeod, A. I. (1995). Diagnostic checking periodic autoregression models with application. Journal of Time Series Analysis, 15, 221-233.

McLeod, A. I., \& Balcilar, M. (2008). Pear: Package for periodic autoregression analysis. R package version 1.0,.http://www.rproject.org.

Obeysekera, J. T. B., \& Salas, J. D. (1986). Modeling of aggregated hydrologic time series. Journal of Hydrology, 86, 197-219.

Osborn, D., Chui, A., Smith, J., \& Birchenhall, C. (1988). Seasonality and the order of integration for consumption. Oxford Bulletin of Economics and Statistics, 50, 361-377.

Smadi, A., \& Abu-Afouna, N. (2012). On the least squares estimation of simple linear regression model with periodically correlated errors: a cautionary note. Accepted in Austrian Journal of Statistics.

Tiao, G., \& Grupe, M. (1980). Hidden periodic autoregressive-moving average models in time series data. Biometrika, 67, 365-373.

Zinde-Walsh, V., \& Galbraith, J. (1991). Estimators of a linear regression model with stationary ARMA(p, q) errors. Journal of Econometrics, 47, 333-357. 